\title{
Das implicações tributárias do desvio de finalidade na destinação do produto arrecadado com a CIDE-combustíveis
}

Flávia Helena Gomes ${ }^{1}$

\begin{abstract}
Resumo
Pelo presente estudo apresentou-se, a partir de uma metodologia dedutiva, uma pesquisa acadêmica acerca das CIDEs e sua autonomia tributária. Identificou-se as normas do regime jurídico desse tributo e a sua regra matriz de incidência tributária. Nesse contexto revelou-se o princípio da proporcionalidade, o qual permite que a contribuição interventiva alcance a sua finalidade, verdadeiro requisito de validade da exação. Também se demonstrou que é traço característico dessas contribuições a destinação do produto arrecadado à finalidade que ensejou a sua instituição. Essa destinação, além de ser contemplada pela lei instituidora do tributo em norma paralela à regra-matriz de incidência, deverá, necessariamente, ser verificada também no plano fático, sob pena de invalidade da própria exação. Buscou-se, assim, por meio da análise da CIDE-Combustíveis caracterizar o desvio do produto arrecadado, e por conseqüência, o desvio da finalidade autorizadora de sua instituição. Com isso, pretendeu-se demonstrar a invalidade desse tributo. Concluiuse, então, pelas implicações tributárias advindas do desvio dos recursos de tal contribuição e apontou-se a existência de um direito subjetivo do contribuinte de questionar judicialmente tal fato, tendo em vista que a destinação encarada apenas como elemento financeiro implicaria a violação da própria natureza desse tributo.
\end{abstract}

Palavras-Chave: Contribuição de Intervenção no Domínio Econômico; Destinação; Desvio; Finalidade; Implicações Tributárias.

\section{Introdução}

As Contribuições de Intervenção no Domínio Econômico (CIDEs), a que se referem os arts. 149 e 177 da Constituição Federal de 1998 suscitam uma série de questões constitucionais e tributárias, especialmente pela função extrafiscal que normalmente assumem, pois vinculam o tributo ao fim constitucional que fundamenta a própria exação e a arrecadação dela decorrente.

Assim, por meio do estudo acerca da característica que confere autonomia a essas contribuições especiais, notadamente as CIDEs, do regime jurídico aplicável a tais exações e

\footnotetext{
${ }^{1}$ Acadêmica do $5^{\circ}$ ano matutino do curso de Direito da Universidade Estadual de Londrina. 0 presente artigo originou-se do Trabalho de Conclusão de Curso realizado sob a Orientação do Professor Ercias Rodrigues de Sousa, Professor do Curso de Direito da UEL Mestre e Doutor em Direito pela PUC-SP.
} 


\section{Das implicações tributárias do desvio de finalidade na destinação do produto arrecadado com a CIDE-combustíveis}

dos elementos componentes de sua regra-matriz de incidência tributária, pretende-se definir qual é o posicionamento jurídico da destinação do produto arrecadado com as CIDEs.

Esse posicionamento iniciará os seguintes embates: será que tal exação será constitucionalmente válida apenas pelo fato de a lei que a instituir contemplar de maneira expressa a sua finalidade? Ou será que essa finalidade dever ser aliada a imposição legal da destinação do produto arrecadado àquela? Essa imposição legal deve ser apenas em abstrato, isto é, basta a sua previsão na norma instituidora da exação, ou será necessária a efetiva aplicação dos recursos arrecadados na finalidade que ensejou o tributo? Ainda, será a questão da efetiva destinação meramente financeira, ou tendo em vista a natureza das CIDEs será também requisito de validade dessa exação?

Com a análise prática da denominada CIDE-Combustíveis, instituída pela Lei 10.336, de 19 de dezembro de 2001, com fulcro no art. 177 da Constituição Federal de 1988, cujo produto arrecadado já encontra destinação no inciso II, § 4으, do mesmo artigo, bem como por meio dos acompanhamentos desenvolvidos pelo Tribunal de Constas da União acerca da aplicação dos recursos arrecadados com a CIDE-combustíveis se verificará a existência ou não de desvio de finalidade na destinação do seu produto. E, uma vez constatado tal desvio, propõe-se 0 atual trabalho a estudar quais as suas possíveis implicações tributárias.

\section{Da autonomia das contribuições especiais}

Inicialmente deve-se analisar qual a característica que confere autonomia às contribuições elencadas no art. 149, da Constituição Federal, denominadas contribuições especiais, que envolvem as contribuições sociais, as contribuições de intervenção no domínio econômico e as contribuições das catego rias profissionais.

As classificações baseadas na hipótese de incidência e base de cálculo ou na vinculação ou não do tributo à atuação estatal resultam apenas na existência de três tributos autônomos, que são: os impostos, as taxas e as contribuições de melhoria. Essas classificações afastam a autonomia das contribuições especiais, concluindo que o regime jurídico aplicado a elas deve ser o mesmo aplicado aos impostos ou às taxas.

Assim, embora o art. 4 - do CTN tenha apontado o fato gerador como único critério a caracterizar os tributos, tal prescrição tem sido insuficiente para distinguir todas as espécies tributárias, com regimes próprios, previstas pela Constituição, conforme adverte 
Luciano Amaro (2004, p. 68). Nesse sentido é importante observar as considerações de Paulo de Barros Carvalho (2005, p. 28 seq..) para uma interpretação sistemática do direito, a qual deve se sobrepor à mera exegese da norma individualmente considerada, tendo em vista as imperfeições lingüísticas cometidas pelo legislador.

Ademais, 0 art. 217 do CTN determinou que as disposições do Código não excluem a incidência e exigibilidade de outras contribuições, o que complementa 0 art. 5ำ, ao mesmo passo que evidencia a qualificação das contribuições como espécie tributária autônoma.

Assim, a Constituição Federal de 1988 instituiu as espécies tributárias denominadas de contribuições especiais no seu art. 149 lhes conferindo tratamento jurídico diferenciado das demais espécies tributárias, destacando-se a destinação específica como requisito para o exercício legítimo da competência tributária, segundo Luciano Amaro, que esclarece

Em verdade, se a destinação do tributo compõe a própria norma jurídica constitucional definidora da competência tributária, ela se torna um dado jurídico, que, por isso, tem relevância na definição do regime jurídico específico da exação, prestando-se, portanto, a distingui-la das outras (2004, p. 62).

Também o Ministro Moreira Alves em voto proferido no RE no 146.733-9/SP, DJU-1 de 06.11.1992, ao discorrer sobre a natureza tributária da contribuição social prevista no art. 195 da Constituição Federal de 1988, reconheceu a classificação qüinqüipartida presente na atual Carta Magna, dividindo os tributos em: impostos, taxas, contribuição de melhoria, contribuições (sociais, de intervenção no domínio econômico e de interesse das categorias profissionais ou econômicas) e empréstimos compulsórios. Nesse sentido, destaca-se o seguinte excerto de seu voto:

De efeito, a par das três modalidades de tributos (os impostos, as taxas e as contribuições de melhoria) a que se refere 0 art. 145 para declarar que são competentes para instituí-los a União, os Estados, o Distrito Federal e os M unicípios, os arts. 148 e 149 aludem a duas outras modalidades tributárias, para cuja instituição só a União é competente: o empréstimo compulsório e as contribuições sociais, inclusive as de intervenção no domínio econômico (RE no. 146.733-9/SP. Fonte: DJU de 06.11.1992).

Portanto, as contribuições enquanto tributos autônomos se destacam, fundamentalmente, por sua vinculação à destinação constitucionalmente imputada, particularidade esta que irá determinar a natureza da contribuição e seu regime jurídico 


\section{Das implicações tributárias do desvio de finalidade na destinação do produto arrecadado com a CIDE-combustíveis}

próprio, concomitantemente ao controle de sua validade, diferenciando as contribuições especiais dos demais tributos.

\section{Das contribuições de intervenção no domínio econômico}

Sabe-se que não é o nome atribuído ao tributo, mas sim o regime jurídico aplicado que lhe confere determinada natureza. Assim, o regime jurídico constitucional irá apresentar os parâmetros para aferição da constitucionalidade das contribuições interventivas, isto é, quais regras constitucionais devem ser obrigatoriamente respeitadas quando da entrada da norma que cria tal exação no ordenamento jurídico, para que possa, então, produzir validamente seus efeitos.

0 art. 149 da CF ao se referir ao art. 146, III inaugura a discussão quanto à necessidade da edição de lei complementar anterior à criação da contribuição interventiva ou de que esta exação deve ser criada por tal espécie normativa.

A exigência de prévia lei complementar ocorre para que os parâmetros gerais sobre a tributação sejam anteriores a criação do próprio tributo, assim tal lei complementar já existe em nosso ordenamento jurídico que é o Código Tributário Nacional. Questiona-se, porém, a aplicação do CTN às CIDEs.

Paulo Roberto Lyrio Pimenta (2002, p. 53 seq..) entende que as normas do CTN se aplicam às CIDEs no que forem com elas compatíveis, ou seja, os dispositivos que determinam normas nacionais do CTN poderão ser aplicados às CIDEs, enquanto outras normas que se especificam aos demais tributos não serão empregadas. Aplicando-se o CTN às CIDEs não é necessário que tais tributos sejam criados por lei complementar. Além disso, não há determinação legal para que as CIDEs sejam criadas através de lei complementar, o que implica a sua instituição por lei ordinária.

O Supremo Tribunal Federal ao analisar o Adicional de Tarifa Portuária julgado no RE no 209.365, cujo Relator foi o Ministro Carlos Velloso, publicado no Diário de Justiça em 7.12.2000, reconheceu a sua natureza de contribuição de intervenção no domínio econômico, bem como declarou a constitucionalidade da lei ordinária $n$ ำ 7.700/88 que 0 instituiu.

Nesse ponto, o presente trabalho partirá da premissa de que o CTN é, sim, a lei complementar exigida pelo art. 149, o qual indica normas sobre a tributação das CIDEs, 
aplicando-se a ela no que Ihe for compatível, e, por conseguinte, não há impedimento de que tal exação possa ser instituída por lei ordinária. Corrobora tal posicionamento a assertiva de M arco Aurélio Greco

Não vejo na Constituição Federal exigência de que as contribuições de intervenção no domínio econômico serem criadas por lei complementar. A remissão que 0 artigo 149 faz ao artigo 146, III refere-se à disciplina prevista no CTN, mas não à indispensabilidade de prévia lei complementar para instituí-la (2001, p. 28).

Aplicam-se também às CIDEs os princípios da legalidade, da irretroatividade e da anterioridade nonagesimal, destacando-se, porém, a aplicação do princípio da proporcionalidade.

Ainda, o principio da proporcionalidade ganha relevância na criação das normas de instituição das CIDEs, sendo verdadeiro parâmetro para o legislador federal que deverá atender ao regime jurídico constitucional demarcado para estas exações concomitantemente à finalidade e determinação de sua destinação.

Este princípio é observado por três critérios: necessidade, adequação e proporcionalidade em sentido estrito.

Aplicando-se esses critérios à instituição das CIDEs a necessidade determina que 0 setor em que irá incidir a contribuição interventiva indique que esta exação é imprescindível e suficiente para alcançar sua finalidade.

Verificada a necessidade de instituição das CIDEs, a adequação obriga a que a intervenção seja compatível com a finalidade, isto é, a contribuição interventiva deve ser necessária ao setor econômico em que incidirá, bem como possibilitar o alcance do objetivo da contribuição. Em exemplo dado por Paulo Roberto Lyrio Pimenta (2002, p. 99) a CIDE que tenha por finalidade promover o desenvolvimento de determinado setor não pode impor aos sujeitos passivos ônus financeiro que impossibilite 0 alcance do objetivo perseguido. 0 critério da adequação também impõe que o sujeito passivo seja integrante do setor no qual há intervenção.

Além da necessidade e adequação ao instituir as CIDEs o legislador terá de observar, ainda, a proporcionalidade em sentido estrito, o que significa que a contribuição interventiva não pode suprimir os demais direitos e garantias constitucionais de forma que 


\section{Das implicações tributárias do desvio de finalidade na destinação do produto arrecadado com a CIDE-combustíveis}

sua limitação ao exercício de outros direitos terá de ser menos onerosa ou gravosa que a própria medida.

Observa-se que é exatamente por meio da proporcionalidade das CIDEs à finalidade que se pretende garantir que a cobrança dessa contribuição não se revele injusta, na medida em que não só a sua arrecadação como também a destinação do produto arrecadado deverão atender aos critérios da proporcionalidade, o que culmina na expressa vinculação do produto arrecadado à finalidade contemplada na lei instituidora das CIDEs.

\section{Do posicionamento jurídico da destinação do produto arrecadado com as CIDES}

É a norma jurídica tributária que insere ao ordenamento jurídico o tributo, possuindo uma estrutura didaticamente denominada por Paulo de Barros Carvalho (2005, p. 253) de regra-matriz de incidência tributária. Apresentou-se que é a finalidade constitucional, no caso, a de intervir no domínio econômico, que autoriza a criação das CIDEs e todo o seu regime jurídico se baliza por tal premissa, e esta finalidade será concretizada pela destinação do produto arrecadado.

Assim, importa saber como a norma jurídica tributária poderá atender às características essenciais das CIDEs, suscitando-se aqui se tal exação será constitucionalmente válida apenas pelo fato de a lei que a instituir contemplar de maneira expressa a sua finalidade (além, é claro, de respeitar os demais requisitos impostos pelo regime jurídico)? Ou será que esta finalidade dever ser aliada à imposição legal da destinação concreta do produto arrecadado a esta finalidade?

Observa-se, inicialmente, que a estrutura da regra-matriz, por revelar a norma jurídica tributária, estabelece a obrigação de cunho tributário apenas entre sujeito ativo e passivo da exação, o que inviabiliza que a destinação do produto arrecadado, obrigação específica do sujeito ativo, integre tal norma.

Porém, a finalidade de tais exações só será concretizada com a efetiva destinação do produto arrecadado, segundo assevera Roque Antonio Carrazza:

Noutro dizer, a regra-matriz constitucional destas contribuições agrega, de modo indissociável, a idéia de destinação. Queremos com tal assertiva sublinhar que, por imperativo da Lei Maior, os ingressos advindos da arrecadação destes tributos devem necessariamente ser destinados à viabilização ou ao custeio de uma das atividades mencionadas no art. 149 da CF (2007, p. 570, grifo nosso) 
Cumpre, então, abordar o posicionamento jurídico da destinação do produto arrecadado com as CIDEs perante a regra-matriz, eis que exerce papel fundamental na caracterização constitucional desse tributo.

Preliminarmente, cumpre esclarecer que não se contesta que a arrecadação é meio hábil à atuação do Estado no domínio econômico, eis que através do manejo do critério quantitativo, especialmente a alíquota, poderá o Estado, ao efetuar o recolhimento da contribuição interventiva, estimular ou desacelerar determinado setor econômico.

Todavia, é essencial destacar a destinação do produto arrecadado com as CIDEs, que também configura instrumento de atuação do Estado no domínio econômico, pois ainda que contemplada a finalidade e mesmo que a própria tributação seja meio desta intervenção, a não aplicação das verbas recolhidas com a contribuição interventiva macularia o próprio objetivo do Estado ao instituir tal exação.

Se o que motiva e autoriza a União a instituir uma contribuição interventiva é exercer influência no domínio econômico, não pode ser outro o destino do produto arrecadado senão a atividade ou situação econômica que a ensejou, o que implica que tal obrigação deve estar contemplada como regra na lei que institui tal exação.

Pretende-se dizer, a partir disso, que a destinação do produto arrecadado é requisito constitucional de validade da exação em tela. Daí a importância de se analisar qual o posicionamento jurídico da destinação do produto arrecadado com as CIDES.

Existem dois posicionamentos doutrinários significantes sobre 0 enquadramento legal da destinação: um no sentido de que basta a previsão legal da destinação do produto arrecadado; e outro que defende a necessidade de que esta destinação seja, além de prevista pela norma, efetivada no plano concreto.

Assim, para a primeira corrente defendida por Paulo Roberto Lyrio Pimenta, Luciano Amaro e Márcio Severo Marques, basta que exista uma norma jurídica financeira paralela a norma de incidência tributária que determine a destinação do produto arrecadado à finalidade interventiva, sendo a concreta destinação apenas ato ilegal do fisco, o que não afetaria a validade do tributo. Dessa forma, qualquer desvirtuamento do produto arrecadado seria questão financeira e se limitaria ao controle dos Atos do Executivo.

Há, também, a segunda situação em que a finalidade é desviada na destinação dos recursos arrecadados, não sendo suficiente a mera previsão legal da destinação das verbas 


\section{Das implicações tributárias do desvio de finalidade na destinação do produto arrecadado com a CIDE-combustíveis}

arrecadadas com as CIDEs ao custeio da intervenção que a originou, sendo imprescindível também a concreta aplicação desses recursos nesse objetivo.

Cumpre frisar que todo o regime jurídico dessa exação, assim como a composição de sua regra-matriz de incidência, é juridicamente justificado pelo alcance de uma finalidade, o que se pauta pelo princípio da proporcionalidade. Tal princípio vincula a todo tempo a exação à necessidade da medida interventiva em determinado setor econômico, a adequação da mesma ao alcance desse objetivo, bem como à estrita proporcionalidade entre o meio, no caso o tributo, e o fim, que é a intervenção no domínio econômico.

De tal modo que se mostra juridicamente impossível verificar 0 alcance da finalidade, bem como justificar-se a razão de ser das CIDEs sem se atentar para a aplicação dos recursos arrecadados com essa exação.

Aliás, as CIDEs possuem regime jurídico próprio e natureza tributária autônoma exatamente por encontrar-se a sua finalidade vinculada à destinação. Caso contrário, descaberia seu regime jurídico próprio derrogatório de certas normas constitucionais, devendo, então, respeitar-se o regime jurídico tributário comum aos impostos.

Nesse sentido, Tácio Lacerda Gama adverte:

É justamente a destinação específica que autoriza a sua criação. Com efeito, se o destino daquilo que se arrecada com esses tributos não for a intervenção específica que ensejou a sua criação, o tributo terá outra natureza, diversa das contribuições. 0 regime jurídico aplicável, por isso, também será diverso. Assim, será possível falar em imposto ou em qualquer outra espécie de exação, exceto em contribuições interventivas (2003, p. 266).

Dessa forma, a destinação do produto arrecadado com as CIDEs deve estar configurada também no plano fático, não bastando, portanto, a previsão em abstrato da norma que as instituir, por meio da norma financeira paralela à regra-matriz, devendo, necessariamente, a lei orçamentária que determinar a aplicação dos recursos arrecadados atender ao fim que ensejou a criação desse tributo. 


\section{Das implicações tributárias do desvio de finalidade na destinação do produto arrecadado com a CIDE-Combustíveis}

Como forma de se discutir uma exação exemplificativa das CIDEs, aplicando seu regime jurídico, bem como possibilitando o alcance dessa finalidade através da verificação da destinação concreta de seu produto e as conseqüências tributárias de seu eventual desvio, é que se escolhe a CIDE-combustíveis, instituída pela Lei no 10.336, de 19.12.2001.

Diferentemente das demais contribuições interventivas, a CIDE-combustíveis é prevista constitucionalmente pelo $\S 40$ do art. 177, o qual foi acrescentado pela EC $n^{0} 33 / 01$. Esse dispositivo expressamente autoriza a criação de CIDE relativa a setor determinado da economia que exerce atividade de importação ou comercialização de petróleo e seus derivados, gás natural e seus derivados e álcool combustível.

A EC no 33/01 também fixou constitucionalmente através do inciso II do $\S 4^{0}$ do art. 177 qual deve ser o destino do produto arrecadado com a CIDE-combustíveis: I - pagamento de subsídios a preços ou transporte de álcool combustível, de gás natural e seus derivados e de derivados de petróleo; II - financiamento de projetos ambientais relacionados com a indústria do petróleo e do gás; e III - financiamento de programas de infra-estrutura de transportes.

Nesse sentido, a Lei no 10.336/01 ao instituir a exação em tela atendeu a previsão

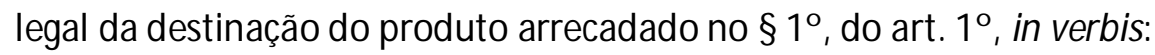

\footnotetext{
$\S 1$ ㅇ 0 produto da arrecadação da Cide será destinada, na forma da lei orçamentária, ao:

I - pagamento de subsídios a preços ou transporte de álcool combustível, de gás natural e seus derivados e de derivados de petróleo;

II - financiamento de projetos ambientais relacionados com a indústria do petróleo e do gás; e

III - financiamento de programas de infra-estrutura de transportes.
}

Porém, além da criação de lei orçamentária, a Lei no 10.336/01 consignou, ainda, que a aplicação dos recursos seria avaliada no ano de 2002, para, então, a partir de 2003, criarem-se critérios e diretrizes em lei específica para tal.

Em 30 de dezembro de 2002 publicou-se a Lei no 10.636 que estipulou os critérios e diretrizes para aplicação dos recursos dessa contribuição, bem como criou o Fundo Nacional 


\section{Das implicações tributárias do desvio de finalidade na destinação do produto arrecadado com a CIDE-combustíveis}

de Infra-Estrutura de Transportes - FNIT, para financiar programas de investimento em infra-estrutura de transportes.

Essa lei possibilitou a justificação da instituição da exação em tela, uma vez que identificou os projetos ambientais relacionados com a indústria do petróleo e do gás, cuja administração compete ao Ministério do M eio Ambiente, segundo o seu art. 4ํㅡ, bem como definiu em seu art. 6o quais são os objetivos dos programas de infra-estrutura de transportes.

Diante das disposições supracitadas se constata que a lei instituidora da CIDEcombustíveis contempla a destinação prevista constitucionalmente, inclusive, estabelecendo, objetivamente, critérios e diretrizes para a aplicação das verbas arrecadadas.

Entretanto, para que essa exação tenha plena validade a destinação do produto arrecadado, nos moldes em que a Lei no 10.336/01 e sua complementação pelas Leis no 10.636/02 e n 10.866/04, deve ser constatada também no plano fático através da efetiva aplicação desses recursos ao subsídio de preços, projetos ambientais e planejamento e melhoramento da infra-estrutura de transportes.

Em seu aspecto prático, a aplicação dos recursos arrecadados com a CIDEcombustíveis nos anos de 2002 e 2003 foi objeto indireto da auditoria realizada no Departamento Nacional de Infra-Estrutura de Transportes (DNIT) sobre a qualidade das obras rodoviárias custeadas com recursos federais pelo Tribunal de Contas da União (TCU), a qual resultou no Acórdão no 938/03.

Acerca do produto arrecadado com a CIDE-combustíveis e a sua aplicação nos anos de 2002 e 2003 o Ministro Relator apresentou um quadro orçamentário que evidencia, através de números oficiais, o desvio de finalidade na destinação dos recursos arrecadados com a CIDE-combustíveis nos exercícios de 2002 e 2003. Destacando-se: a aplicação de menos de 1\% em 2002 e menos de 2\% em 2003 desse saldo no meio ambiente, o que sequer pode inferir que está relacionado aos prejuízos ambientais causados pela indústria do petróleo, gás e álcool; a constatação de ausência de subsídios aos preços de combustíveis, gás e seus derivados; a aplicação de significativo montante do percentual destinado a infraestrutura de transportes para custear o setor administrativo, como pagamento de servidores, "auxílios" e até com propaganda; e a retenção desses valores para compor a reserva de contingência (TCU. Acórdão no 9 938/03. Disponível em: 
«ttp://contas.tcu.gov.br/portaltextual/

Mostra

Docum

ento $p=1 \& d o c=2 \&$ templ $=$ default $\& q n=1>$. Acesso em: 28 maio 2008.).

Não obstante o desvio das verbas arrecadadas com a CIDE-combustíveis previstas em orçamento, a Lei $n-10.640$, de 13.01.03, que fixou as receitas e despesas para 0 exercício desse ano previu também a autorização da criação de créditos suplementares para suprir outras despesas não previstas por meio da utilização de $10 \%$ do valor já consignado em orçamento, o que permitiria o desvirtuamento de outras quantias aplicadas com a CIDEcombustíveis.

Em atenção a essa possibilidade a Confederação Nacional dos Transportes propôs Ação Direta de Inconstitucionalidade no 2.925-8 para conferir à Lei Orçamentária no 10.640/03, em especial ao seu art. 40, I, alienas "a" a "d", que autoriza a abertura de créditos suplementares, interpretação conforme 0 art. 177, § 4ํ, II, "a", "b" e "c" da CF. Tal Ação visou, principalmente, a alertar que tanto a permissão quanto a aplicação de recursos da CIDE-combustíveis em finalidade diversa daquela imputada constitucionalmente no inciso II do $\S 4^{\circ}$ do art. 177 ofendem o texto constitucional e devem ser afastadas.

Prevaleceu a preocupação da maioria dos Ministros em resguardar o texto constitucional perante a constatação prática do desvio de finalidade na destinação do produto arrecadado com a CIDE-combustíveis perpetrada através de interpretação extensiva da Lei Orçamentária no 10.640/03, culminando no seguinte acórdão:

LEI ORÇAMENTÁRIA - CONTRIBUIÇÃO DE INTERVENÇÃO NO DOMÍNIO ECONÔMICO - IMPORTAÇÃO E COMERCIALIZAÇÃO DE PETRÓLEO E DERIVADOS, GÁS NATURAL E DERIVADOS E ÁLCOOL COMBUSTIVEL - CIDE - DESTINAÇÃO ARTIGO 177, § 40, DA CONSTITUIÇÃO FEDERAL. É inconstitucional interpretação da Lei Orçamentária no 10.640, de 14 de janeiro de 2003, que implique abertura de crédito suplementar em rubrica estranha à destinação do que arrecadado a partir no disposto no $\S 4$ o do artigo 177 da Constituição Federal, ante a natureza exaustiva das alíneas "a", "b" e "c" do inciso II do referido parágrafo. (BRASIL. Supremo Tribunal Federal - STF. ADIn no 2.925-8/DF. Inicial disponível em: বhttp://www.stf.gov.br/portal/geral/ verP dfPag inado. asp? $i d=181928 \&$ tipo $=T P \&$ descricao $=A D I \% 2 F 2925>$ Acesso em: 30 maio 2008.)

Tal decisão, embora tenha tido como objeto a Lei Orçamentária no 10.640/03, abriu precedente no sentido de que a lei orçamentária não pode dotar os recursos arrecadados com a CIDE-combustíveis em outro setor ou finalidade senão aqueles determinados 


\section{Das implicações tributárias do desvio de finalidade na destinação do produto arrecadado com a CIDE-combustíveis}

constitucionalmente pelo inciso II, § 4 ㅇ do art. 177 da CF, nem tão-pouco pode criar crédito suplementar alocando verbas dessa contribuição que contraria a referida disposição constitucional.

Porém, nota-se que esses preceitos continuaram a ser desrespeitados na elaboração das Leis Orçamentárias seguintes, pois continuaram prevendo créditos suplementares sem a ressalva da vinculação do produto arrecadado com a CIDEcombustíveis às finalidades constitucionais.

Além da interpretação extensiva que o Poder Executivo confere às leis orçamentárias, criou um mecanismo legal acrescentando a art. 76 ao Ato das Disposições Constitucionais Transitórias por meio da EC $n 0$ 42/03, o qual permitiu, ainda, a desvinculação de vinte por cento do produto arrecadado pelas contribuições sociais e de intervenção no domínio econômico.

Nesse panorama o Tribunal de Contas da União promoveu em 2005 um acompanhamento dos recursos da CIDE-combustíveis que resultou no Acórdão № 1857/05. Esse acompanhamento requereu informações dos órgãos que recebem os recursos da CIDEcombustíveis (M inistérios dos Transportes, da Fazenda e do Planejamento, Orçamento e Gestão) acerca da aplicação desse produto. Nas respostas desses órgãos e dados técnicos colhidos demonstra-se que o quadro alertado pelo Acórdão no 938/03 permaneceu: a aplicação do produto direcionado ao setor de infra-estrutura de transportes sendo aplicado em despesas de recursos materiais e humanos; a alocação desses recursos em outros setores diversos daqueles relacionados às ações previstas no inciso II, § 4ㅇ do art. 177 da CF; a alocação em reserva de contingência; e a retenção de recursos arrecadados no exercício financeiro para gerar superávit primário.

O Min. Marcos Vinicios Vilaça esclareceu quem deve se beneficiar dos recursos da exação em tela:

Entretanto, verifica-se, com base no inciso II do $\S 40$ do art. 177 da Constituição Federal, que os beneficiários dos recursos da Cide-Combustíveis não são órgãos ou unidades orçamentárias, tampouco esfera orçamentária (fiscal, seguridade social ou investimentos), mas as ações orçamentárias, quais sejam: os programas de infra-estrutura, de financiamento de projetos ambientais e o pagamento de subsídios. Neste sentido, não parece ser adequada a destinação de recursos da Cide-Combustíveis para atividades não diretamente associadas a tais fins (BRASIL. Tribunal de Contas da União - TCU. Acórdão no 1857/05. Rel. M in. Marcos Vinicios Vilaça. Publicado DOU em 28.11.05. Disponível em: 
বhttp:// contas.tcu.gov.br/portaltextual/ MostraDocumento? qn $=2 \& d o c=2 \& d p p=20$ $\& p=0>$. Acesso em: 28 maio 2008, grifo nosso)

Além disso, consta do referido acórdão do TCU que embora a Lei ํo 10.636/02 tenha previsto a criação do Fundo Nacional de Infra-Estrututa de Transportes - FNIT para gerir os recursos da CIDE-combustíveis dessa área, essa disposição não foi implementada devido ao veto presidencial quanto à destinação dos recursos arrecadados ao FNIT, prevista no inciso I do art. 11 da mesma lei.

Desse modo, constata-se que o desvio de finalidade na destinação do produto arrecadado com a CIDE-combustíveis é evidenciado em diversas formas transversas de aplicação dos recursos advindos dessa exação, sendo que as dificuldades alegadas pelo Poder Executivo decorre de mecanismos criados por ele mesmo, como a Desvinculação das Receitas da União, as reservas de Contingência e contingenciamento, bem como através de vetos a qualquer tentativa de implementação do FNIT para gerir os valores arrecadados coma a CIDE-combustíveis.

Tomando ciência do Acórdão o 1857/05 do TCU, o Procurador-Geral da República ajuizou, em 08.10.07, Ação Direta de Inconstitucionalidade visando declarar a inconstitucionalidade, sem redução de texto, de qualquer interpretação que autorize a utilização dos recursos arrecadados coma CIDE-Combustíveis fora das hipóteses traçadas nos arts. 177, § 4ㅇ, II, "a", "b" e "c" da Constituição, em especial para o custeio de custeio de despesas correntes da Administração e para a geração de superávit financeiro-orçamentário no balanço de pagamentos.

A ADIn № 3970 ainda aguarda julgamento, sendo essa discussão de extrema importância para a validade da CIDE-combustíveis, pois caracterizado o desvio na destinação do produto arrecadado com essa exação, também se evidencia que não há intervenção no domínio econômico, eis que o Estado não atua concretamente subsidiando preços de petróleo e seus derivados, gás natural e seus derivados e álcool combustível, tão-pouco promovendo projetos ambientais ligados aos riscos ao meio ambiente ocasionados por esse setor da indústria, bem como não investindo em projetos e obras da infra-estrutura de transportes. Fato incontroverso que desnatura a própria autorização constitucional que ensejou a instituição dessa contribuição. 


\title{
Das implicações tributárias do desvio de finalidade na destinação do produto arrecadado com a CIDE-combustíveis
}

Do exposto, resta evidenciado que a destinação concreta conferida à CIDEcombustíveis não contempla a finalidade elevada a status constitucional pelo inciso II, § 40 , art. 177 da CF, sobrepondo-se as leis orçamentárias ao intuito consignado na própria Carta Magna, ultrapassando os limites do regime jurídico constitucional impostos a essa exação, como bem arremata o M inistro M arcos Vinicios Vilaça do TCU. Vejamos:

\begin{abstract}
Ora, a natureza interventiva, nobre e excepcional da contribuição não comporta utilização que não a dignifique. Não há qualquer merecimento numa tributação especial que se preste a proporcionar auxílio-alimentação, como se evidencia. Certamente, os cidadãos não foram sobretaxados, de forma tão incomum, para colaborar com a manutenção da máquina administrativa. Se este fosse um dos objetivos da contribuição, não me parece que o legislador constituinte a aprovaria (BRASIL. Tribunal de Contas da União - TCU. Acórdão no 1857/05. Rel. Min. Marcos Vinicios Vilaça. Publicado DOU em 28.11.05. Disponível em: বhttp://contas.tcu.gov.br/portaltextual/ MostraDocumento? qn $=2 \& d o c=2 \& d p p=20$ $\& p=0>$. Acesso em: 28 maio 2008.).
\end{abstract}

Resta evidente que a aplicação de $R$ \$ 10.775 bilhões em rubricas orçamentárias totalmente dissociadas da prescrição que o legislador constitucional fez questão de estabelecer não se trata de uma discussão meramente financeira. Pois, não foi a CIDEcombustíveis criada para atingir o escopo constitucional determinado nas alíneas "a", "b" e "C" do inciso II, § 4º, art. 177?

Não parece razoável, portanto, especialmente frente ao quadro de repetidas interpretações do Poder Executivo contrárias ao disposto na própria Constituição, que se ignore o evidente desvio de finalidade perpetrado na transversa aplicação dos recursos da CIDE-combustíveis como fato que fere a validade dessa exação.

Logo, outra não pode ser a conclusão senão a de que a cobrança da CIDEcombustíveis resta inválida pela dotação desvirtuada que seus recursos reiteradamente vêm recebendo, desde sua criação, por parte do Poder Executivo, o que macula a própria razão de ser desse tributo, implicando a sua inconstitucionalidade. Para atacá-la duas vias poderão ser eleitas: o controle de constitucionalidade concentrado genérico ou o controle difuso.

0 meio mais acessível ao contribuinte é o controle difuso em que poderá requerer a declaração da inconstitucionalidade da CIDE-combustíveis cumulada com o pedido de repetição de indébito.

Entretanto, não se pode ignorar a realidade do entendimento jurisprudencial no sentido de que a efetiva destinação é mera questão financeira, não ofendendo, por isso, a 
validade da exação, muito embora não tenha se submetido à apreciação judicial o quadro oficialmente apresentado pelo Tribunal de Contas da União como meio probatória do desvio do produto arrecadado com a CIDE-combustíveis, limitando-se a discussão jurisdicional ao plano teórico.

Também se observa que as Ações Diretas de Inconstitucionalidade no 2.925-8 e no 3.970 não visam à inconstitucionalidade da exação, muito embora alertem que a não aplicação dos recursos arrecadados às finalidades determinadas no inciso II, § 4º , art. 177 da CF ferem a própria Constituição, buscando apenas a interpretação conforme 0 texto constitucional.

Por certo que o montante arrecadado com a CIDE-combustíveis se extinto causaria sérios transtornos para o orçamento da União, bem como não se pretende aqui desconfigurar a nobre intenção do legislador constitucional que inseriu tal contribuição em nossa Carta magna para viabilizar a intervenção Estatal em áreas tão imprescindíveis ao setor de comercialização de petróleo e seus derivados, gás natural e seus derivas e álcool combustível.

Ocorre que o contribuinte não pode ficar à mercê da interpretação que o Poder Executivo conferirá a cada exercício financeiro à correta aplicação dos recursos arrecadados com a CIDE-combustíveis, ainda mais quando a própria Constituição é expressa sobre essa destinação.

Portanto, ainda que se afaste a inconstitucionalidade do desvio de finalidade na destinação do produto arrecadado com a CIDE-combustíveis, não se pode deixar de reconhecer a flagrante ilegalidade da conduta do Poder Executivo, eis que comprovadamente não tem observado preceitos constitucionais. Tal situação implicará na motivação de pedido de restituição do tributo pelo contribuinte, fundado na ilegalidade da conduta do Fisco.

Deduz-se que tanto a interpretação de que a ausência de efetiva destinação do produto arrecadado com a CIDE-combustíveis macula a exação de inconstitucionalidade, quanto a que entende se tratar de ato ilegal do Poder Executivo culminam no direito do contribuinte de questionar judicialmente tal fato.

Tal conclusão leva ao significado de segurança jurídica, o qual segundo Paulo de Barros Carvalho é um sobreprincípio, posto que permite, além da realização de seu próprio 


\section{Das implicações tributárias do desvio de finalidade na destinação do produto arrecadado com a CIDE-combustíveis}

conteúdo axiológico, a realização de outros princípios de maior hierarquia (apud LIMA; LÔBO, 2004, p. 59). Ressalva-se quanto ao aludido princípio a necessidade de o mesmo ser empírico, conforme a advertência do referido autor:

Sendo assim, de nada adiantam direitos e garantias individuais, placidamente inscritos na Lei Maior, se os órgãos a quem compete efetivá-los não o fizerem com a dimensão que o bom uso jurídico requer.

[...]

Não haverá respeito ao sobreprincípio da segurança jurídica sempre que as diretrizes que 0 realizarem venham a ser concretamente desrespeitadas e tais situações infringentes se perpetuem no tempo, consolidando-se (CARVALHO apud LIMA; LÔBO, 2004, p. 60).

Assim, o contribuinte não pode se submeter à inconsistência da aplicação de determinação constitucional por parte do Poder Executivo, pois uma vez configurado que desde a criação da CIDE-combustíveis os recursos arrecadados não recebem a destinação constitucional que originou a exação, há flagrante ofensa não só à segurança jurídica, como também aos demais princípios componentes do regime jurídico desse tributo.

Reconhece-se, ainda, a dificuldade do judiciário penetrar no campo de ação concreta das leis orçamentárias, eis que nesses casos a conduta administrativa é vinculada, porém, não se pode vedar que o contribuinte levante a discussão, uma vez que cumpriu a sua obrigação jurídico-tributária, da inobservância da aplicação do montante arrecadado com a CIDE-combustíveis na finalidade que originou tal obrigação.

Portanto, em respeito ao fundamento constitucional de existência da CIDEcombustíveis, bem como ao princípio da segurança jurídica, não é afeto ao bom sendo jurídico admitir que a alocação de seu produto arrecadado em despesas não adstritas àquelas relacionadas no inciso II, § 4ํㅡ, art. 177 da CF não fira a validade dessa exação, o que merece maior atenção e respeito por parte do Poder Judiciário e Poder Executivo.

\section{Conclusão}

0 estudo das diversas classificações doutrinárias dos tributos permitiu verificar a existência da classificação qüinqüipartida, a qual confere autonomia às contribuições especiais previstas no art. 149 da Constituição Federal, bem como se identifica como sua principal característica a destinação de seu produto à finalidade que a ensejou. 
Observou-se, também, que o regime jurídico constitucional das CIDEs impõe que esta contribuição de competência exclusiva da União seja instituída por lei ordinária, aplicando-se a ela no que Ihe for compatível o Código Tributário Nacional. As contribuições interventivas deverão obedecer, ainda, aos princípios da legalidade, irretroatividade, anterioridade e anterioridade nonagesimal.

Destaca-se dentro do regime jurídico das CIDEs o princípio da proporcionalidade, eis que será verdadeiro parâmetro para que o legislador federal atenda ao regime jurídico constitucional demarcado para estas exações concomitantemente à finalidade e determinação de sua destinação.

Assim, diante do regime jurídico exposto pelo presente trabalho, resta evidente que é a finalidade constitucional, no caso, a de intervir no domínio econômico, que autoriza a criação das CIDEs e todo o seu regime jurídico se baliza por tal premissa.

Essa premissa, portanto, é requisito fundamental para a inserção válida da norma jurídica de incidência tributária das CIDEs no ordenamento jurídico pátrio, o que implica que deve nortear todos os critérios que compõem a regra matriz de incidência, dando coerência à natureza jurídica dessa exação.

Não obstante a finalidade a ser contemplada na regra-matriz de incidência tributária das contribuições interventivas, também a destinação do produto arrecadado com essas contribuições deve ser elemento de sua validade, posto que the confere autonomia perante os demais tributos.

Nesse aspecto, o posicionamento jurídico da destinação do produto arrecadado com as CIDEs impõe a previsão legal, paralela à norma jurídica de incidência tributária, da destinação de seus recursos, concluindo-se que essa prescrição não deve ser tão-somente abstrata, mas, necessariamente, constatada no plano fático.

Daí a importância para o presente estudo da análise de uma CIDE em cobrança, sendo a escolha pela CIDE-combustíveis decorrente da previsão constitucional da destinação de seus recursos determinada pelo inciso II, $\S 40$, do art. 177, da CF.

Em análise da CIDE-combustíveis, instituída pela Lei 10.336, de 19 de dezembro de 2001, verificou-se que essa lei contemplou abstratamente a destinação do produto arrecadado, inclusive com a descrição dos projetos ambientais e de infra-estrutura de transportes a serem implementados, conforme acréscimos ef etuados pela Lei № 10.636/02. 


\section{Das implicações tributárias do desvio de finalidade na destinação do produto arrecadado com a CIDE-combustíveis}

Entretanto, ao analisar a efetiva destinação dos recursos arrecadados às ações

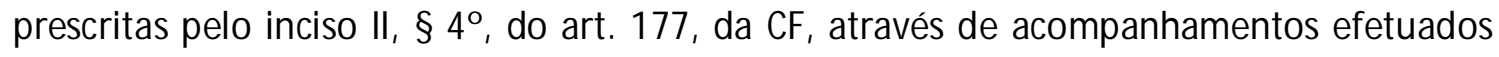
pelo Tribunal de Contas da União, resultantes nos Acórdãos no 938/2003 e 1857/2005, restou evidenciado flagrante desvio de finalidade na destinação do produto arrecadado com a CIDE-combustíveis.

Essa contribuição interventiva, por sua própria natureza, possui uma finalidade, a qual deve ser impreterivelmente proporcional à medida, o que apenas é possível com a aplicação efetiva dos recursos arrecadados a esse objetivo. Daí a necessidade de se identificar também no campo tributário quais as implicações desse desvio de destinação, o qual macula a própria razão de ser da exação.

Aliás, afirmar que o desvio de finalidade na destinação do produto arrecadado com a CIDE-combustíveis é mera questão financeira, ficando adstrita ao controle dos atos do Poder Executivo, é negar a própria essência e autonomia da exação.

Dessa forma, o comprovado e inegável desvio de finalidade na destinação do produto arrecadado com a CIDE-combustíveis implica a sua inconstitucionalidade, cabendo ao contribuinte, via controle de constitucionalidade difuso, ajuizar ação de repetição de indébito com fundamento na invalidade da exação decorrente do aludido desvio. E ainda que se entenda seja uma questão financeira, o desvio de finalidade na destinação dos recursos dessa contribuição constitui ato ilegal do Poder Executivo, o que também dá ensejo legal ao pedido de restituição.

Por fim, a discussão acerca das implicações tributárias do desvio de finalidade na destinação do produto arrecadado com a CIDE-combustíveis é campo fértil à mudança de entendimento jurisprudencial, com destaque para o julgamento pendente da ADIn no 3970, e até mesmo de responsabilização do Poder Executivo, o que não pode impedir o acesso do contribuinte a esse questionamento em atenção ao princípio da segurança jurídica inerente ao sistema tributário constitucional.

\section{Referências}

AM ARO, Luciano. Direito tributário brasileiro. 10. ed. São Paulo: Saraiva, 2004.

BRASIL. Tribunal de Contas da União - TCU. Acórdão № 1857/05. Rel. M in. Marcos Vinicios Vilaça. Publicado DOU em 28.11.05. Disponível em: 
«ttp://contas.tcu.gov.br/portaltextual/M ostraDocumento? $q n=2 \& d o c=2 \& d p p=20 \& p=0$. Acesso em: 28 maio 2008.

BRASIL. Supremo Tribunal Federal - STF. ADIn no 2.925-8/DF. Inicial disponível em: বttp:// www.stf.gov.br/portal/geral/verPdfPaginado.asp?id=181928\&tipo $=T P \& d e s c r i c a 0=A$ DI\%2F2925>Acesso em: 30 maio 2008.

CARRAZZA, Roque Antônio. Curso de direito constitucional tributário. 23. ed. São Paulo: Malheiros, 2007.

CARVALHO, Paulo de Barros. Curso de direito tributário. 17. ed. São Paulo: Saraiva, 2005.

GAM A, Tácio Lacerda. Contribuição de intervenção no domínio econômico. São Paulo: Quartier Latin, 2003.

GRECO, M arco Aurélio. Contribuições de intervenção no domínio econômico e figuras afins. São Paulo: Dialética, 2001.

LIM A, Aristóteles M oreira; LÔBO, M arcelo Jatobá. Questões controvertidas em matéria tributária: uma homenagem ao professor Paulo de Barros Carvalho. Belo Horizonte: Fórum, 2004.

M ARQUES, Márcio Severo. Classificação constitucional dos tributos. São Paulo: Max Limonad, 2000.

PIM ENTA, Paulo Roberto Lyrio. Contribuiç̧ões de intervenção no domínio econômico. São Paulo: Dialética, 2002.

TCU. Acórdão no 938/03. Disponível em: «ttp:// contas.tcu.gov.br/portaltextual/ M ostraDocumento? $p=1 \&$ doc $=2 \&$ templ=default $\& q n=1>$. Acesso em: 28 maio 2008. 